\title{
Study of Global Solar Radiation Potential and Ground Level Albedo at Benevento Italy
}

\author{
${ }^{1}$ Khem N. Poudyal, ${ }^{2}$ Pasquale Daponte, ${ }^{2}$ Serjio Rapone, ${ }^{1}$ Binod K Bhattarai, \\ ${ }^{1}$ Balkrishna Sapkota, ${ }^{3}$ Berit Kjeldstad \\ ${ }^{1}$ Institute of Engineering, Tribhuvan University, Kathmandu, Nepal \\ ${ }^{2}$ University of Sannio, Benevento, Italy \\ ${ }^{3}$ Norwagian University of science and technology, Norway \\ E-mail: khem100@hotmail.com
}

\begin{abstract}
Global solar irradiance iwas measured by a calibrated pyranometer (model LP PYRA 05 Delta Ohm ISO 9060) at about 1 meter off the roof top of building of the University of Sannio, Benevento, Italy (latitude $41^{\circ} 08^{\prime} \mathrm{N}$ longitude $14^{\circ} 45^{\prime} \mathrm{E}$ and $150.0 \mathrm{~m}$ ), from April to June 2010. This site is about $50.0 \mathrm{~km}$ north east of the Naples costal area so there are fluctuations in the local weather condition. Still, there was a significant amount of intensity in global solar irradiation found. The maximum solar radiation of about $659.47 \mathrm{~W} / \mathrm{m}^{2}$ was found at 11:00 AM with clear sky conditions on May 2010 at Benevento, Italy. The maximum and minimum value of ground level albedo, 0.74 and 0.32, was found at 6:00 AM and 11:00 AM respectively. This indicates that the daily measured data of horizontal global solar radiation decreases with an increase in ground level albedo. Besides this, we concluded that there was a high level of fluctuation in the measured value of solar irradiance due to local weather conditions. The results of the research can be utilized for the conformation of variation of solar radiation due to wind speed, humidity and environmental pollution. This study will help to estimate the global solar irradiance potential available to solar energy systems at Benevento, where the average global soar irradiance is estimated to be about $5.0 \mathrm{kWh} / \mathrm{m}^{2}$.
\end{abstract}

Key words: global irradiance, reflected irradiance, albedo; atmospheric pollution, potential

\section{Introduction}

Energy generated by the sun is radiated outwards in all directions and only two thousandmillionths of it is intercepted by the earth as light and infrared (heat) radiation. The intensity of the sun's radiation at the top of the earth's atmosphere at the mean distance of the earth from the sun is roughly constant. This constant is also called the solar constant and its measured or observed value is about 1366 Watts $/ \mathrm{m} 2 \pm 0.3 \%$. However, on average, only about half of this energy reaches the earth's surface. The total quantity of short wave radiant energy emitted by the sun as well as that scattered diffusively by the atmosphere and clouds, passing through a unit area in the horizontal in unit time is referred generally as global solar radiation. Monitoring the daily global solar radiation will help in assessing the total solar energy at any location considering diurnal and seasonal variations. The global solar radiation reaching the earth's surface is made up of two components, direct and diffuse. The sum of the direct and diffuse components reaching a horizontal surface is global radiation. Direct radiation is the part, which travels unimpeded through space and the atmosphere to the surface; and diffuses radiation is the part scattered by atmospheric constituents such as molecules, aerosols, and clouds. In simple terms, direct radiation causes shadows, and diffuse is responsible for skylight [1]. 
Solar energy is a clean, pollution free, and renewable source of energy. Development of this source of energy requires an accurate detailed long-term knowledge of the potential taking in to account seasonal variations. The region of the Italy expands in between the latitude of $42^{\circ} 50^{\prime} \mathrm{N}$ and longitude of $12^{\circ} 50^{\prime} \mathrm{E}$. Some parts lie in the solar belt and others are very close (Solar Belt is about $40^{\circ} \mathrm{N}$ to $40^{\circ} \mathrm{S}$ from the equatorial regions). Thus this region is supposed to be with an abundant amount of solar radiation to harvest the solar energy.

Benevento is the capital of the province, $50 \mathrm{~km}$ northeast of Naples. It is situated on a hill about $150 \mathrm{~m}$ above sea-level. It is located between the latitude $41^{\circ} 08^{\prime} \mathrm{N}$ and $14^{\circ} 45^{\prime} \mathrm{E}$ longitude and the geographic position favors the harvesting and development of solar energy. In Italy the average global solar radiation range is about 3.8-6.4 kWh/sq.m [2]. Global solar radiation during winter is very low as compared to summer season because of rainy season as well as the dense cloud. The study identifies that coastal parts of Italy with the higher global solar radiation is ideally suited for harvesting solar energy. This study has demonstrated to find out the global solar radiation potential, as well as to calculate the ground level albedo at the Benevnto. For the estimation of global solar irradiance it is necessary to measure the diffuse radiation as well as beam radiation. Besides this it is urgent to measure the temperature, precipitation, wind speed, altitude, albedo, ground level ozone, environmental pollution. In addition that it is necessary to find out the actual change in climate and scattering factors thus it will more convenient to design the solar energy plants. In spite of this, if we measure more key parameters which are directly dependence on global solar radiation continuously it will help to validate with satellite data and finally we can develop the solar map and on the basis of solar map we can able to develop the model.

At the same time the ground base measurement data and GIS base satellite data can be utilize and it will provided the means for identifying, and quantifying the factors affecting the available solar energy potential. In spite of this, it also provides the flexibility to enrich the database, on which decisions are based, with spatial data and additional restriction on resource availability.

Albedo is defined as the ratio of the energy reflected back to the incident energy. It is unitless quantity. In meteorology the reflectance is also called albedo. This quantity varies with $\alpha$ and $\beta$ where $\alpha$ is called wavelength exponent and $\beta$ is called Angstrom's turbidity coefficient. It is greater at the shorter wavelengths because more energy is scattered in the shorter than in the longer wavelengths. Thus It means that the albedo increases with $\beta$ and $\alpha$. Larger value of $\alpha$ represents the small average particle size, and we know that smaller particles scatter more energy than do bigger particles. Generally the albedo for snow is about 0.7 or more than that. Similarly the multiply reflected irradiance ground level albedo varies from the range of 0.20 to 0.70 . Sometime it may changes with turbidity and wavelength, size of particles and nature of the surface whether it may bright or deems [3]

Actually, solar energy is not economically competitive with conventional alternatives if we consider capital costs, operating and maintenance costs and financial costs. However, considering the actual situation about the greenhouse effects and the oil depletion perspective, many countries including Italy have already passed laws that provide financial incentives to encourage an early adoption of solar energy technologies. Government of Italy have given the top priority to promote the renewable energy resources including solar energy but due to the lack of funding problems its development is slow motion in comparisons to other European countries. This energy contributes to the sustainable development of the 21 st century civilization [4]. 


\section{Energy Scenario of Italy}

The Mediterranean country's solar boom is likely to continue for the next several years, thanks to recently adopted changes to its feed-in tariff scheme and a new national authorization process for solar projects. In the second quarter of 2010, Italy's solar market grew by 127 percent over the previous quarter, according to research and consulting firm Solarbuzz. That means it is on track to reach its goal of doubling its solar capacity in 2010, aiming for a total installed capacity of about 2,500 megawatts (MW). In the longer term, the country hopes to have 8,000 MW installed by 2020 . "We forecast a sustained growth path, thanks to the stable government support to the development of renewable energies and to the establishment of a solid and highly professional market of solar PV market operators. Prothea, which develops rooftop and Greenfield solar photovoltaic projects, recently completed the authorization process for four solar projects totaling 11 megawatts, and has more than 50 megawatts worth of projects in its development pipeline. The company says the country's feed-in tariff scheme and expected cost reductions for solar materials are supporting its growth, while a pending move to establish national guidelines for authorizing solar projects could speed development timelines [5].

Italy government is far from the targets set at both the national and European level. It is happened due to several reasons. Firstly, there is a large element of uncertainty due to recent political changes and ambiguities in the current policy design. Secondly, there are administrative constraints such as complex authorization procedures at local level. Thirdly, there are financial barriers such as high grid connection costs. In Italy, there is an obligation the obligation on electricity generators to produce a certain amount of Renewable Energy Resources (RES). At present, the Italian government is working out the details of more ambitious support mechanisms for the development and use of RES in Italy, Europe's third-biggest solar power producer after Germany and Spain, gets less than one percent of its power from PV installations at present.But industry body GIFI has estimated that PV capacity will see exponential growth to 16,000 megawatts (MW) in 2020 from about $280 \mathrm{MW}$ in 2008, fueled by the government incentives and Europe's renewable energy targets [6].

\section{Materials and Methods}

For the measurement of incident global solar radiation and the reflected global solar radiation we use two pyranometers mounted back-to-back, one looking upward (sky) and other one downward (earth). The upward pyranometer measures the incident global radiation (direct + diffuse) striking the ground, while the downward pyranometer is also called albedometer which measures the global radiation reflected from the ground. The output of the two pyranometers electric signals can be directly sent to a data logger to an automatic data processor. Albedo is the fraction of solar radiation that is reflected from the ground, with respect to the incident global radiation. These two calibrated pyranometers which made up of the LP PYRA 05 Delta Ohm ISO 9060 are coupled in order to have the same sensitivity. These types of actinometers are used to measure broadband solar irradiance on a planar surface and shadow-less open space. These instruments are installed at about 1 meter off roof top of Building of the University of Sannio Benevento (latitude $41^{\circ} 08^{\prime} \mathrm{N}$ longitude $14^{\circ} 45^{\prime} \mathrm{E}$ and $150.0 \mathrm{~m}$ ) Italy since April to June 2010.

There is a sensor that is designed to measure the global solar radiation flux density (in watts per meter square) from a field of view of 180 degrees. The device which measures the radiation which comes from the sun through sky is called pyranometer. Its main components are glass dome, metal body, black sensor, radiation screen, level and cable. These pyranometers do not 
require the power to operate. The thermopile sensor creates the temperature difference and the temperature difference is proportional to the potential difference which is a voltage output. When the output terminal connects to the data logger then it converts the voltage into intensity of radiation directly in the $\mathrm{W} / \mathrm{m}^{2}$ unit. This pyranometer is used to measure the global solar radiation within the one minute interval of time for 24 hours. In the mean time we measure the incident global solar irradiance and it will compare to theoretical value for the conformation of actual potential of global solar irradiance. In addition that it is used to calculate the reflectivity (albedo) by using reflected global solar irradiance and incident global solar irradiance.

\section{Data and Results}

In our research work we measured the solar irradiance regularly from April to June 2010. Fig. No. 1 is drawn across solar irradiance versus local time and the measured value gives the nearly similar trend with actual trend.By using statistical tools we found that the correlation coefficient is 0.974 in between measured solar irradiance and trend line which is highly significance data to investigate the global solar irradiance potential at this location. Thus the result shows that there sufficient amount of solar energy is available in this region.

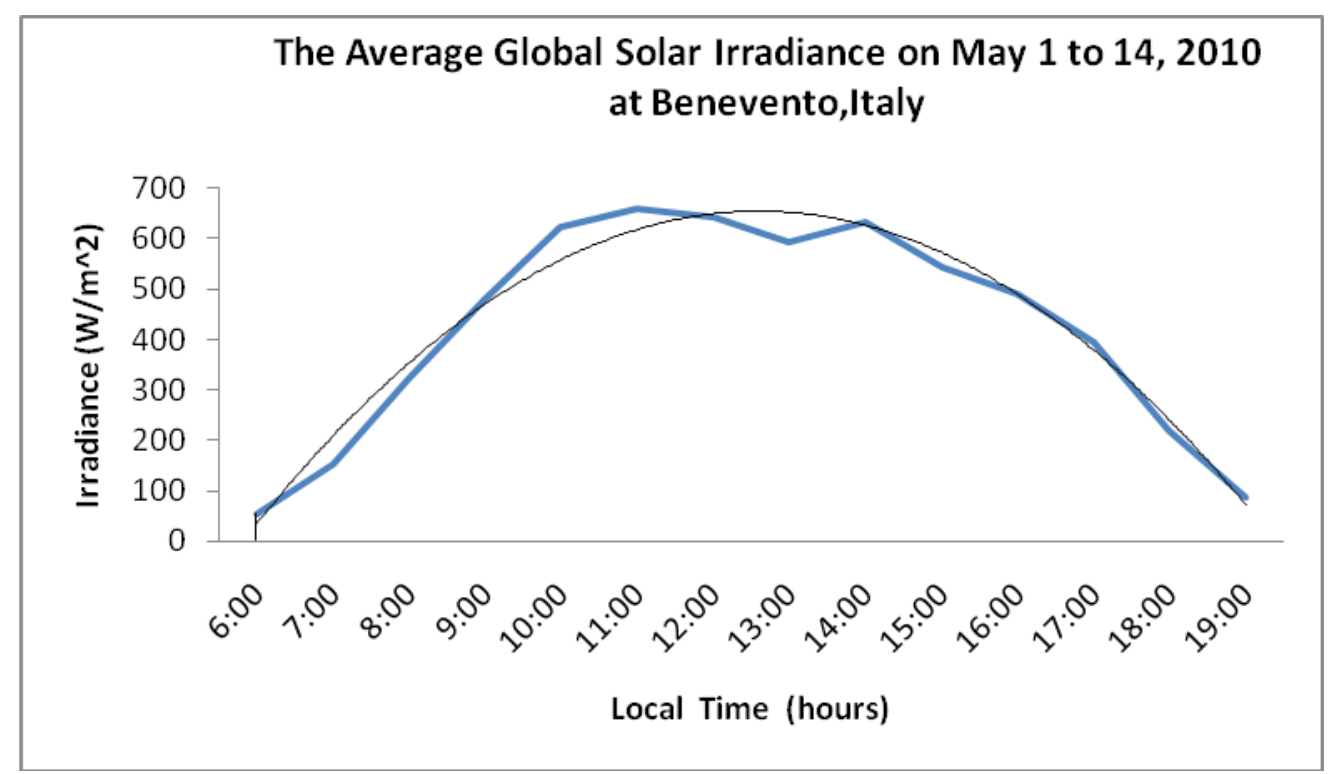

Fig. No.1. The Average Global Solar irradiance on the May 1 to 14, 2010 at Benevnto Italy

Fig. No. 2. Gives the comparative study in between the measured data of global solar irradiance with theoretical data and there is strong agreement between them. But in some time there s highly fluctuate the measured data to the calculated data due to the changing the local weather conditions such as wind speed, cloud and humidity. 


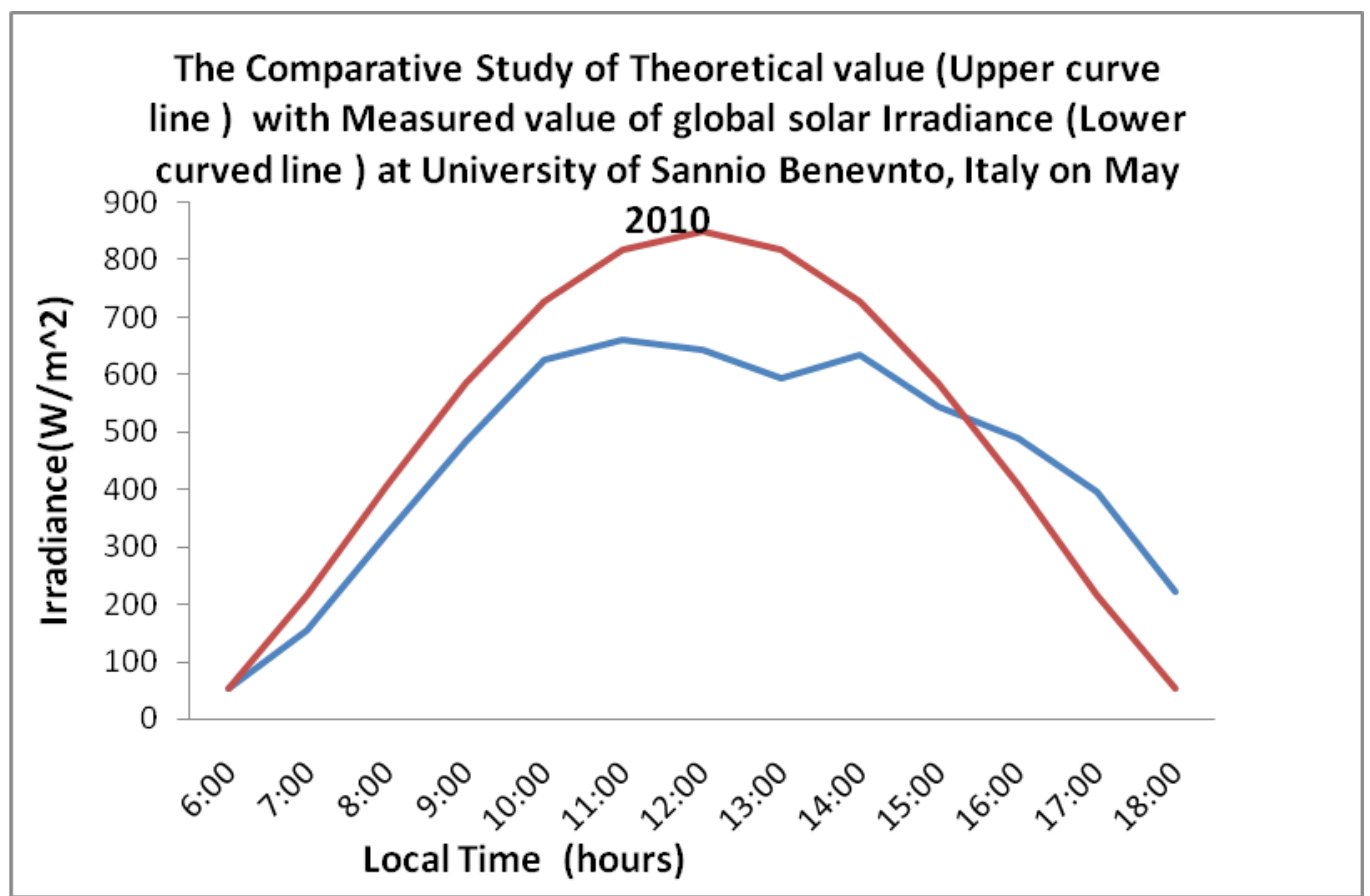

Fig. No.2. The comparative study of theoretical value of global solar irradiance with measured value of global solar irradiance at the University of Sannio Benevento Italy in May 2010

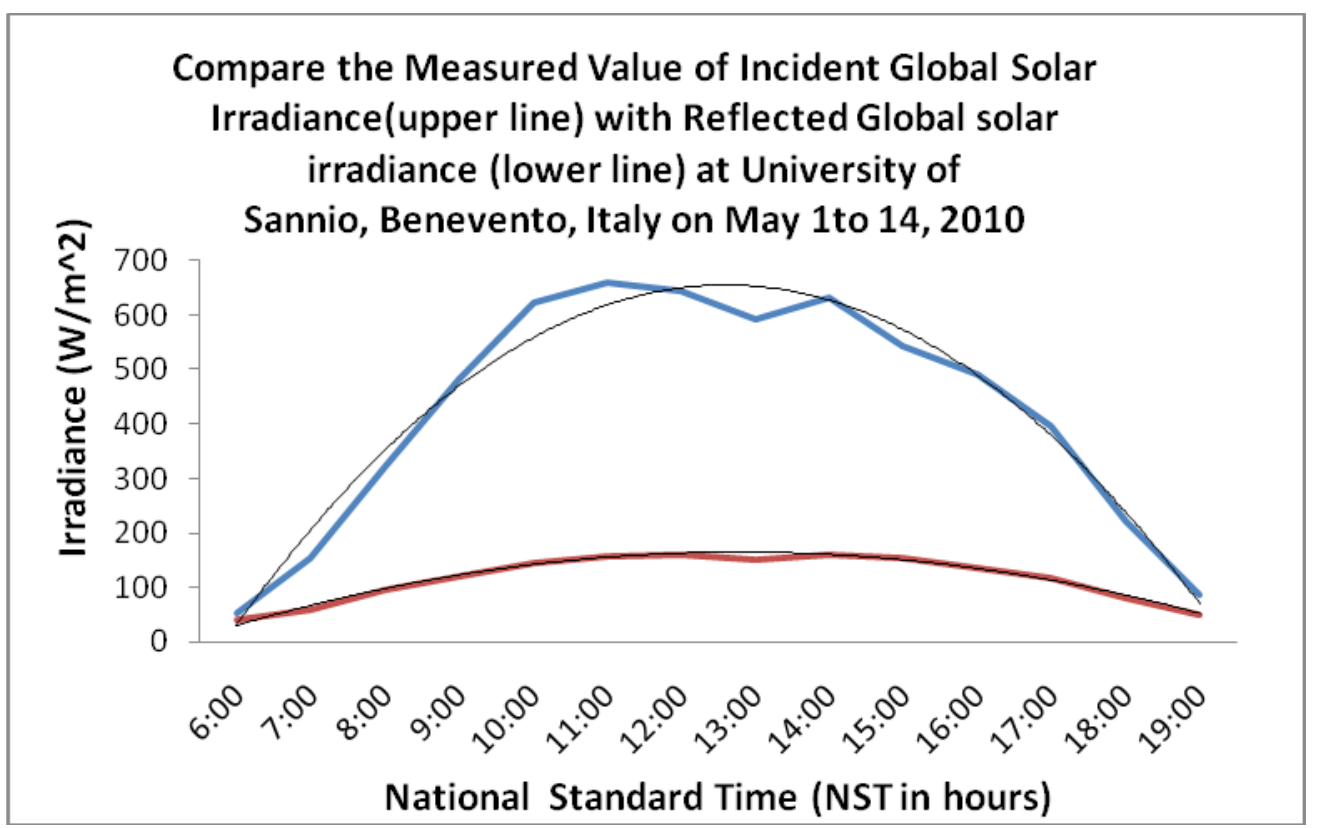

Fig. No.3. Compare the measured value of incident global solar irradiance with reflected global solar irradiance at University of Sannio Benevento Italy on May 2010.

It is well known that for the actual estimation of value of global solar irradiance potential at the allocated place we should measure the beam radiation, diffuse radiation, albedo, reflected 
radiation and other possible parameters then those data will be realizable and we can validate the measured data with satellite data finally it will easy to reach at the conclusion.

Fig. No. 3 is drawn across solar irradiance versus national standard time then there is very strong relation in between direct global solar irradiance and reflected global solar irradiance. There is 0.974 and 0.983 are the correlation coefficient of direct global solar irradiance and reflected irradiance respectively. This figure indicates that there very high variation of direct global solar irradiance in comparision with reflected global solar irradiance.

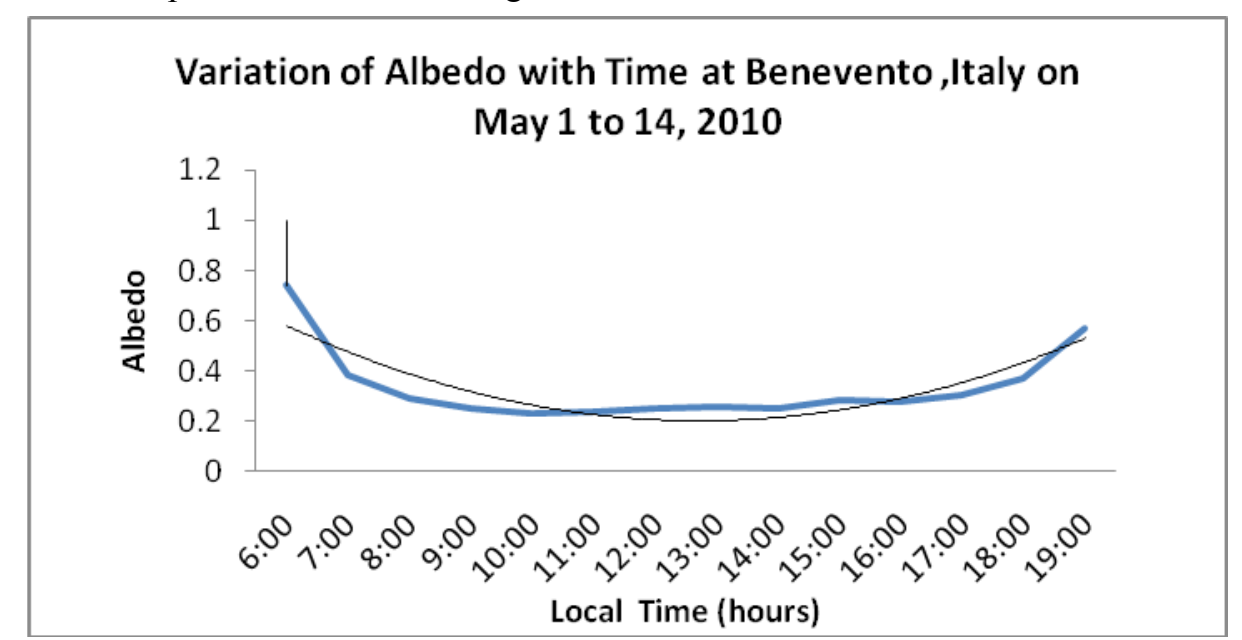

Fig.4. Variation of Albedo with Time at Benevento, Italy on May 2010

Fig.4. showed that the ratio of incident global solar irradiance to the reflected global solar irradiance (ground level albedo ) is minimum at the mid day and greater at the morning and evening time. It means that the ground level albedo depends upon the humidity, surface of the ground and environmental pollution. In addition that, in general the earth's surface is a poor reflector of the solar radiation although the amount of reflection varies greatly with the nature of the surface. On the earth surface the light colored objects reflect more than dark color [7]. Thus in our experiment, the albedo is comparatively low because of brown and deem color of the surface. There is 0.8 correlation coefficient with trend line it means that the given result is meaningful in terms of variation of global solar irradiance.

\section{Conclusions}

In our research work there is a strong correlation in between experimental result and theoretical result. It means that our analysis is meaningful. It is found that the global solar irradiance potential is sufficient to generate energy at the Benevento Italy. Similarly there is good agreement in between incident global solar irradiance and reflected global solar irradiance. On the basis of this result we are succeed to calculate the ground level albedo its ranges from 0.32 to 0.7 at the early morning and before noon. Albedo is one of the key parameter to affects the global solar irradiance.

Finally it is concluded that the Benevento Italy is favorable to harvest the solar energy because there is sufficient amount of global solar irradiance as well as the average solar insolation is about $5.0 \mathrm{kwh} / \mathrm{m}^{2}$ which is one of the highest in Europe. Another reason is that Italy has big energy crisis. They import huge amount of oil and gases from other countries thus they should 
promote solar energy technology aggressively to reduce the import in energy as well as to preserve the environment itself.

\section{Acknowledgement}

We are grateful to express our sincere thanks to Department of Engineering Measurement Section University of Sannio for providing all the necessary instruments and support to do research work, Solar Radiation and Aerosol in Himalaya Region (SAHR) project of IOE Pulchowk (Nepal) for providing the pyranometer instruments to gain the practical experiences, We are grateful to Assis. Prof. N B Amatya, HOD of Engineering Science and Humanities, IOE Pulchowk, for his support in our research activities. Special thanks go to friends.

This paper is a part of work under eLINK Project for which we would like to express special thanks to Prof. M.Savino, Prof. Luca Di Vito University of Sannio Italy for his support and encouragement during this research work, Prof. R Rijal, eLINK local coordinator and Executive Chairman of Kantipur Engineering College (KEC).Nepal.

\section{REFERENCES}

[1] Albert Millar et.al "Elements of Meteorology" Fourth Edition, 1987 pp 58

[2] Claudia Furlan1, Amauri Oliveira and Jacyra Soares, Università degli Studi di Padova,Brazil, "A Model for Diffuse Solar Radiation in Presence of Some Environmental Parameters"

[3] http://www.reuters.com/article/idUS253307450420100922

[4] http://www.scienzagiovane.unibo.it/English

[5] Muhammad Iqbal "An Introduction to Solar Radiation Academic Press 1983 pp 152-154

[6] Renewable Energy Policy Review Italy 2009 pp 1-2

[7] T.V. Ramachandra, Energy Education Science and Technology, Indian Institute of Science, Bangalore, India 2007 Volume (issue) 18(2): 101-114 